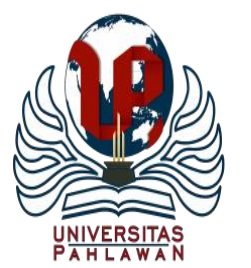

Jurnal Abdidas Volume 2 Nomor 5 Tahun 2021 Halaman 1037-1042

JURNAL ABDIDAS

http://abdidas.org/index.php/abdidas

\title{
Pelatihan Perancangan RPP Tematik Kepada Guru SD Di Kecamatan Marpoyan Damai
}

\author{
Febrina Dafit $^{1 凶}$, Elpri Darta Putra ${ }^{2}$ \\ Pendidikan Guru Sekolah Dasar, Universitas Islam Riau, Indonesia ${ }^{1,2}$ \\ E-mail : febrinadafit@edu.uir.ac.id ${ }^{1}$ elpri.dp@edu.uir.ac.id ${ }^{2}$
}

\begin{abstract}
Abstrak
Kegiatan pengabdian kepada masyarakat ini dilatarbelakangi oleh masih kurangnya pemahaman guru SD dalam penyusunan RPP tematik. Pembelajaran yang dilakukan oleh guru masih terpaku pada RPP mata pelajaran, padahal RPP mata pelajaran kurang sesuai dengan kemampuan berpikir siswa SD dan kurang sesuai dengan Kurikulum 2013 yang berlaku pada saat ini. RPP mata pelajaran seyogyanya kurang sesuai dengan kemampuan berpikir siswa SD yang masih berfikir secara holistik. Hal inilah yang mendasari perlunya dilakukan kegiatan pengabdian ini dengan tujuan untuk membantu guru SD khususnya guru SD di kecamatan Marpoyan Damai dalam merancang dan menyusun RPP tematik sehingga proses pembelajaran yang dilaksanakan bagi siswa sekolah dasar akan semakin bermakna dan berkualitas. Dari hasil pengabdian diketahui bahwa guru merasa perlu memahami konsep penyusunan RPP tematik dalam proses pembelajaran, hal ini didapat guru melalui pelatihan dan panduan yang telah diberikan. Selain itu, hasil pengabdian juga menunjukkan bahwa guru dapat memahami prosedur penyusunan RPP tematik dengan baik. Kesimpulan hasil pengabdian adalah guru memahami bagaimana prosedur penyusunan perangkat RPP tematik.
\end{abstract}

Kata kunci: perancangan, RPP, tematik, guru sekolah dasar

\section{Abstract}

This community service activity is motivated by the lack of understanding of elementary school teachers in the preparation of thematic lesson plans in elementary schools. The learning carried out by teachers is still fixated on the lesson plans, even though the lesson plans are not in accordance with the thinking abilities of elementary school students and are not in accordance with the 2013 curriculum that is currently in effect. Lesson lesson plans should not be in accordance with the thinking skills of elementary school students who still think holistically. This is what underlies the need for this service activity with the aim of helping elementary school teachers in designing and compiling thematic lesson plans so that the learning process carried out for elementary school students will be more meaningful and quality. The result of this service is that it is hoped that elementary school teachers who are participants in the service can understand the preparation of thematic lesson plans in accordance with existing guidelines. In addition, this service is expected to provide new knowledge concepts for participants so that they can carry out better learning in elementary school classes.

Keywords: design, lesson plans, thematic, elementary school teachers

Copyright (c) 2021 Febrina Dafit, Elpri Darta Putra

$\triangle$ Corresponding author

Address : Universitas Islam Riau

Email : febrinadafit@edu.uir.ac.id

DOI : https://doi.org/10.31004/abdidas.v2i5.425

ISSN 2721- 9224 (Media Cetak)

ISSN 2721- 9216 (Media Online) 
1038 Pelatihan Perancangan RPP Tematik Kepada Guru SD Di Kecamatan Marpoyan Damai - Febrina Dafit, Elpri Darta Putra

DOI: https://doi.org/10.31004/abdidas.v2i5.425

\section{PENDAHULUAN}

Pembelajaran tematik adalah pembelajaran yang utuh dan menyeluruh sehingga dapat mengembangkan aspek pengetahuan, sikap serta keterampilan oleh siswa. Pembelajaran ini menggunakan tema-tema yang dekat dengan kehidupan siswa, sehingga pembelajaran dapat lebih bermakna dengan siswa mencari sendiri dan menemukan apa yang akan mereka pelajari (Hidayah, 2015 : 36).

Proses pelaksanaan pembelajaran harus memperhatikan Rencana Pelaksanaan Pembelajaran (RPP) yang telah dirumuskan sebelumnya oleh seorang guru agar prosedur pelaksaan pembelajaran terlaksana dengan baik. Perencanaan pembelajaran disusun untuk kebutuhan guru dalam melaksanakan tugas mengajar. RPP atau rencana pelaksanaan pembelajaran merupakan gambaran prosedur yang dikembangkan oleh guru untuk mencapai kompetensi dasar yang telah ditetapkan dalam standar isi (Prastowo, 2015 : 145). Rencana pelaksanaan pembelajaran tatap muka digunakan satu pertemuan atau lebih agar pembelajaran berlangsung secara interaktif, inspiratif, menyenangkan, menantang, efisien, dan memotivasi peserta didik untuk berpartisipasi aktif, kreativitas, kemandirian sesuai dengan bakat minat serta psikologis peserta didik. RPP mendorong para pendidik untuk mampu merancang, melaksanakan dan menilai pembelajaran yang menguatkan karakter yang religiositas, nasionalisme, kemandirian, gotong royong dan integritas. Dalam setiap kegiatan pembelajaran nilai utama tersebut perlu dijadikan sebagai poros utama dalam membangun karakter peserta didik.

Kurikulum 2013 merupakan kurikulum yang menjadikan pembelajaran menjadi pembelajaran bertema sehingga RPP yang digunakan juga harus RPP tematik (Permendikbud Nomor 81a Tahun 2013.). RPP tematik berbeda dengan RPP biasa, perbedaan utamanya terletak pada tema yang digunakan. Jika pada RPP biasa pembelajaran dipisahkan sesuai dengan mata pelajaran, pada RPP tematik beberapa mata pelajaran akan dipadukan dalam satu tema. Pentingnya penyusunan RPP tematik di sekolah dasar dapat dilihat dari kemampuan pemahaman dan perkembangan usia siswa. Siswa sekolah dasar dengan rentang usia 7-12 tahun berada tahap perkembangan berpikir operasional konkrit, implikasi dari tahap perkembangan ini adalah siswa masih memandang sesuatu secara holistik (keseluruhan), sehingga siswa akan lebih mudah memahami sesuatu apabila dibelajarkan melalui benda-benda konkrit dan bergantung pada pengalaman yang dialaminya. Apabila pembelajaran dilakukan secara terpisah untuk setiap mata pelajaran, nantinya dapat berdampak pada kurang berkembangnya cara berpikir holistik pada siswa (Rusman, 2015 : 65).

Pembelajaran tanpa perencanaan cenderung mengalami kegagalan karena tidak memiliki acuan apa yang dilakukan dalam mencapai keberhasilan pembelajaran. Beberapa faktor yang membuat pendidik tidak membuat RPP diantaranya; karena tidak memahami hakekat RPP, prinsip penyusunan RPP, apa pentingnya RPP. Apalagi dengan adanya perubahan sistematika dalam RPP ada yang 
1039 Pelatihan Perancangan RPP Tematik Kepada Guru SD Di Kecamatan Marpoyan Damai - Febrina Dafit, Elpri Darta Putra

DOI: https://doi.org/10.31004/abdidas.v2i5.425

mengatakan RPP karakter, RPP balon dan sekarang ini dengan istilah RPP Inspirasi yang disusun secara sistematis sesuai dengan Permendikbud No.22 Tahun 2016. Perbaikan RPP (disebut RPP balon dan RPP Inspirasi) setiap tahapan disesuaikan dan diintegrasikan ditandai sendiri dengan dikotak atau digaris miring dengan memasukkan penilaian Hots, Integrasi 4C, integrasi Literasi dan PPK (Perpres No. 87 Tahun 2017).

Pengembangan RPP mengacu pada Undangundang No 19 Tahun 2005 tentang Standar Nasional Pendidikan, yang mana dijelaskan bahwa dalam RPP sekurang-kurangnya memuat tujuan pembelajaran, materi pembelajaran, metode pembelajaran, sumber belajar dan penilaian hasil belajar. Perbedaan antara pengembangan RPP mata pelajaran dengan RPP tematik tampak pada tema pemersatu yang digunakan. Jika pada RPP mata pelajaran, pembelajaran didasarkan kepada mata pelajaran tertentu maka pada RPP tematik didasarkan pada tema atau subtema yang berfungsi mengikat beberapa mata pelajaran(Kadir, 2014 : $35)$.

Pembelajaran tematik dengan menggunakan RPP tematik awalnya sudah mulai diterapkan di sekolah dasar sejak berlakunya Kurikulum 2004, namun penerapannya masih belum sesuai dengan harapan. Pemahaman guru yang beragam tentang penyusunan RPP tematik menjadi penyebab munculnya masalah ini. Walaupun pemerintah telah melakukan berbagai upaya seperti penataran guru, seminar, KKG, lokakarya, bahkan program sertifikasi guru serta penerapan kurikulum 2013, namun masih banyak guru yang belum melaksanakan pembelajaran tematik di sekolah dasar (Suadnyana, dkk 2016 : 63). Pembelajaran disekolah dasar masih didominasi dengan pembelajaran yang fokus pada satu mata pelajaran seperti Bahasa Indonesia, matematika, IPA, IPS dan lainnya.

Berdasarkan hasil analisis lapangan, menemukan bahwa sebagian besar guru-guru sekolah dasar belum terlalu memahami proses pembuatan RPP tematik dan pelaksanaan pembelajaran tematik dengan baik. Sehingga sebagian besar guru masih merasakan pemilahan di dalam pelaksanaan kurikulum 2013. Masih ada batasan-batasan di dalam pembelajaran antar bidang studi, padahal sudah melaksanakan pembelajaran bertema. Seharusnya siswa tidak bisa membedakan lagi mana pelajaran IPA, matematika, IPS, bahasa Indonesia, dll. Tidak hanya itu, kurangnya pemahaman guru pada pembelajaran tematik juga berdampak pada ketidakmampuan guru dalam menyusun RPP tematik. Sehingga guru kurang mampu menyesuaikan pelaksanaan pembelajaran dengan karakteristik siswa (Undang-Undang Nomor 19 Tahun 2005). Berdasarkan hal inilah dilakukan kegiatan pelatihan penyusunan RPP tematik bagi guru-guru sekolah dasar di Kecamatan Marpoyan Damai. Kegiatan pengabdian ini dimaksudkan untuk meningkatkan pengetahuan dan pemahaman guru akan penyusunan RPP tematik, serta membantu guru memahami bentuk pelaksanaan pembelajaran tematik di sekolah dasar. Maka tujuan pengabdian ini adalah tujuan pengabdian ini adalah (1) Memberi latihan dan pengembangan keterampilan bagi guru untuk menyusun Rencana 
1040 Pelatihan Perancangan RPP Tematik Kepada Guru SD Di Kecamatan Marpoyan Damai - Febrina Dafit, Elpri Darta Putra

DOI: https://doi.org/10.31004/abdidas.v2i5.425

Pelaksanaan Pembelajaran Tematik di sekolah dasar; (2) Memberikan pemahaman bagi guru-guru terhadap pembelajaran tematik di sekolah dasar.

\section{METODE}

Kegiatan pengabdian kepada masyarakat ini dilaksanakan di SD Negeri 193 Kecamatan Marpoyan Damai Kota Pekanbaru. Waktu kegiatan pengabdian pada bulan Januari 2020. Sesuai dengan tujuan pengabdian bagian pendahuluan, disusunlah upaya penyelesaian masalah yang terjadi dengan melaksanakan kegiatan "Pelatihan Perancangan RPP Tematik Kepada Guru-Guru Sekolah Dasar di Kecamatan Marpoyan Damai”. Penerapan upaya dilakukan dengan dua pendekatan yaitu pendekatan klasikal dan pendekatan individu. Pendekatan klasikal dilakukan dengan cara penyampaian hal-hal teoritis dalam bentuk kegiatan workshop, sedangkan pendekatan individual dilakukan dengan kegiatan pendampingan membimbing guru dalam menyusun RPP tematik. Langkah-langkah kegiatan dalam pengabdian ini adalah sebagai berikut.

1. Penjelasan konseptual dari pembelajaran tematik.

2. Penjelasan konseptual tentang alur dan prosedur penyusunan RPP tematik berdasarkan ketentuan yang telah ada.

3. Praktik penyusunan RPP tematik menggunakan panduan yang telah disusun.

4. Pendampingan yang dilakukan oleh dosen kepada guru-guru dalam upaya melakukan kegiatan penyusunan RPP tematik.
5. Pelaksanaan penilaian terhadap RPP tematik yang telah dibuat untuk mengetahui pemahaman guru dalam merancang dan menyusun RPP tematik setelah diberikan pelatihan.

\section{HASIL DAN PEMBAHASAN}

Kegiatan pengabdian ini dilaksanakan di ruang guru SDN 193 kota Pekanbaru. Kegiatan pelatihan dilaksanakan selama satu hari, yaitu pada tanggal 12 Januari 2020 mulai pukul 13.00 hingga pukul 16.00 diluar jam efektif belajar. Berikut diuraikan tahapan pelaksanaan kegiatan pengabdian pada masyarakat di SDN 193 Pekanbaru.

1. Tahap persiapan

Tahap persiapan diawali dengan mempersiapkan segala keperluan alat dan penunjang pelatihan serta melengkapi materimateri pelatihan yang akan disampaikan pada guru-guru SD. Materi yang disampaikan, antara lain tentang: (a) hakikat RPP tematik; (b) karakteristik RPP tematik; (c) komponen RPP tematik; (d) prinsip penyusunan RPP tematik; (e) alur dan komponen penyusunan RPP tematik. Tahap persiapan lain yang dilakukan adalah melengkapi sarana dan prasarana keterlaksanaan pengabdian, seperti proyektor, pengeras suara dan lain-lain.

2. Tahap pelaksanaan

Tahap ini dilaksanakan dengan menyampikan materi yang sifatnya umum dan teoritis. Penyampaiaan materi dilaksanakan oleh ketua pelaksana dimana materi pelatihan ada pada modul yang telah diberikan kepada guru-guru 
1041 Pelatihan Perancangan RPP Tematik Kepada Guru SD Di Kecamatan Marpoyan Damai - Febrina Dafit, Elpri Darta Putra

DOI: https://doi.org/10.31004/abdidas.v2i5.425

SD di Kecamatan Marpoyan Damai. Setelah penyampaian materi oleh ketua pelaksana, guru-guru dipersilahkan untuk memberikan pertanyaan terkait RPP tematik yang tidak dimengerti atau dipahami guru. Selain itu, pada tahap ini guru-guru diberikan kesempatan untuk membuat rancangan pembelajaran tematik sesuai dengan format yang telah dibagikan.

\section{Tahap evaluasi}

Tahap ini dilaksanakan dengan kegiatan evaluasi hasil dari kerja yang telah dilakukan oleh peserta pelatihan.

Berdasarkan hasil pelaksanaan pengabdian maka observasi awal yang dilakukan oleh tim pelatihan menemukan beberapa permasalahan yang terjadi sehingga guru-guru mengalami kesulitan dalam merancang RPP tematik. Permasalahan tersebut diantaranya kurangnya informasi yang didapatkan guru terkait dengan cara merancang RPP tematik, tidak adanya contoh dari RPP tematik yang sudah baik dan tepat untuk digunakan, serta masih kurangnya kemampuan guru dalam memadukan mata pelajaran menjadi pembelajaran tematik.

Produk dari pelatihan ini adalah peserta pelatihan dapat membuat rancangan RPP tematik yang baik dan sesuai dengan format yang sudah ada. Dari pelaksanaan kegiatan pelatihan didapatkan bahwa pelatihan ini memang perlu dilaksanakan sebagai satu upaya untuk memotivasi guru-guru SD memadukan mata pelajaran menjadi pembelajaran tematik, agar pembelajaran yang dilaksanakan memang sesuai dengan kondisi dan kebutuhan siswa SD itu sendiri. Selain itu, pengetahuan guru dalam merancang RPP tematik nantinya juga dapat dimanfaatkan guru untuk mengembangkan kemampuan dalam melaksanakan Penelitian Tindakan Kelas (PTK).

Dilihat dari antusias peserta pelatihan, kegiatan ini perlu dilakukan secara berkesinambungan agar dapat memberikan pemahaman yang lebih baik pada guru-guru yang menjadi peserta pelatihan pembuatan RPP tematik. Kegiatan pelatihan ini memberi pemahaman pada guru tentang RPP tematik, dan juga memberi pemahaman dalam memadukan mata pelajaran sehingga dapat diaplikasikan dalam bentuk kegiatan belajar mengajar. Hal lain yang juga didapatkan peserta melalui kegiatan pelatihan ini adalah memahami cara merumuskan sub tema, merumuskan indikator dan tujuan pembelajaran yang baik, dan menentukan metode pembelajaran yang sesuai.

Mitra dalam pengabdian masyarakat berkontribusi aktif di dalam pengabdian ini karena mitra merupakan peserta di dalam pengabdian. Mitra memberikan sumbangsih tenaga dan pikiran di dalam kegiatan yang dimulai dari perencanaan hingga evaluasi. Mitra adalah guru-guru SDN 193 Pekanbaru yang membutuhkan pelatihan tentang RPP tematik dan memahami bagaimana prosedur pembuatan dan pelaksanaan RPP tematik yang baik dan benar.

Berdasarkan pelaksanaan yang telah dilakukan ada beberapa yang menjadi evaluasi dari kegiatan ini sehingga menjadi perbaikan untuk kegiatan berikutnya yaitu: (1) Sebaiknya pelaksanaan dilaksanakan beberapa kali sehingga pelatihan lebih efektif (2) Pelaksanaan dengan 
1042 Pelatihan Perancangan RPP Tematik Kepada Guru SD Di Kecamatan Marpoyan Damai - Febrina Dafit, Elpri Darta Putra

DOI: https://doi.org/10.31004/abdidas.v2i5.425

waktu yang sangat terbatas tidak memberikan hasil yang maksimal. Keberlanjutan program ini adalah pendampingan pembuatan RPP tematik untuk guru-guru SDN 193 Pekanbaru, diharapkan dengan adanya pendampingan tersebut guru-guru bisa membuat RPP tematik dengan baik dan benar dan dapat menerapkannya di dalam kelas. Berikut salah satu hasil dokumentasi pengabdian ini.

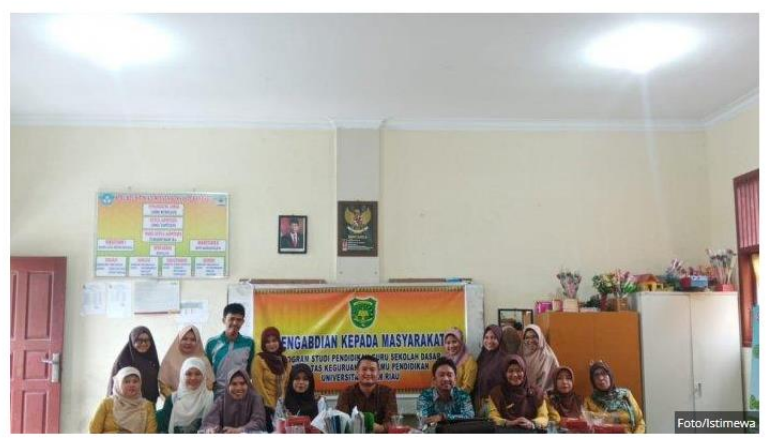

Gambar. Foto Bersama Pemateri dengan beberapa peserta

\section{SIMPULAN}

Kegiatan pengabdian pada masyarakat difokuskan pada perancangan RPP tematik pada guru-guru sekolah dasar. Kegiatan dilaksanakan sesuai dengan perencanaan dan telah mencapai sasaran yang diharapkan. Kegiatan pengabdian ini memberi pemahaman pada guru-guru bagaimana merancang RPP tematik yang baik serta dapat membuat sendiri RPP tematik dengan format yang telah dibagikan. Hal lain yang juga menjadi nilai tambah dari kegiatan pelatihan yang diberikan adalah para peserta pelatihan dapat mengembangkan kemampuan merancang RPP tematik untuk melaksanakan Penelitian Tindakan Kelas.

\section{UCAPAN TERIMA KASIH}

Terimakasih kepada Lembaga Penelitian dan Pengabdian Masyarakat (LPPM) Universitas Islam Riau (UIR) yang telah mendanai pengabdian ini.

\section{DAFTAR PUSTAKA}

Hidayah, N., Pgmi, J., Tarbiyah, F., \& Keguruan, D. (2015). Tematik Sd. Terampil Pendidikan Dan Pembelajaran Dasar, 2, 34-49.

Kadir, Abd dan Asrohan, Hanum. (2014). Pembelajaran Tematik. PT Raja Grafindo Prenamedia Group.

Permendikbud Nomor 81a Tahun 2013 tentang Implementasi Kurikulum 2013.

Prastowo, Andi. (2015). Menyusun Rencana Pelaksanaan Pembelajaran (RPP) Tematik Terpadu Implementasi Kurikulum 2013 untuk SD/MI. Jakarta : Prenadamedia Group.

Rusman. (2015). Pembelajaran Tematik Terpadu. Jakarta : PT Raja Grafindo Persada.

Sudnyana, dkk. (2015). Pelatihan Penyusunan RPP Tematik Integratif Menggunakan Pendekatan Saintifik bagi Guru-guru Sekolah Dasar Gugus VIII Abiansemal Badung Tahun Pelajaran 2015-2016. International Journal Community Service Learning, Vol 1 (1) hal 63-66.

Undang-undang Nomor 19 Tahun 2005 tentang Standar Nasional Pendidikan.

Perpres No.87 Tahun 2017. 